\title{
No Home Bias in Ghost Games
}

\author{
By Alexander Dilger ${ }^{*} \&$ Lars Vischer ${ }^{ \pm}$
}

\begin{abstract}
Because of the COVID-19-pandemic the men's first German football league (Bundesliga) had to take a break before it was permitted to finish the season 2019/20. However, only ghost games without spectators in the stadiums were allowed in this finishing phase. Comparing these 83 games without spectators with the corresponding 83 regular games between the same teams with spectators before, we find that the normal advantage for the home team disappears. There were $48.2 \%$ home wins with spectators and only $32.5 \%$ without. This decrease is statistically significant. There were 32.5\% away wins before the break and $44.6 \%$ thereafter, while the draws increased from $19.3 \%$ to $22.9 \%$. However, these increases are not statistically significant. One reason for the lost home advantage is the disappearance of a home bias by the referees, who gave significantly less extra time and also less yellow and red cards to the away team.
\end{abstract}

Keywords: Bundesliga, COVID-19, football, ghost games, home bias

\section{Introduction}

Ernst Happel once said "a day without football is a lost day" (Deutscher Fußball-Bund 1999, p. 456). The COVID-19 pandemic has had a massive impact on the professional sports industry, in addition to broad social restrictions, and has led to unplanned days without football. As a result, the first German football league (Bundesliga) of men was temporarily suspended on 16 March 2020 and reopened on 16 May 2020 as the first major sports league to do so with significant restrictions (Deutscher Fußball-Bund 2020). The most striking restriction was the exclusion of the public in the stadium. The fact that the current 2019/20 season was interrupted and then resumed with the same team compositions opens up unique research opportunities.

In particular, the influence of the spectators on the outcome of the game can be investigated. Home bias is considered to be one of the best documented phenomena across all sports (e.g., Courneya and Carron 1992, Pollard and Gómez 2014, Pollard and Pollard 2005). A relative advantage exists if the probability of winning a home game is higher than that of losing. Although the home bias diminishes over the years (Biermann 2011, pp. 79-82) and may vary from league to league, it is not to be dismissed. Only the reasons for the home bias are discussed such as the journey of the away team, the familiarity of the home ground, the influence of the spectators, the tactical orientations or the refereeing behaviour (Pollard 2008, Sutter and Kocher 2004). The unique experiment, which was

\footnotetext{
*Professor, University of Münster, Germany.

${ }^{ \pm}$Research Associate and Doctoral Student, University of Münster, Germany.
} 
carried out involuntarily, in the season that finished on 27 June 2020 enables to concentrate on the spectators as the object of research.

In contrast to a study already conducted on ghost games by Reade et al. (2021), the ghost games in this season are neither individual cases in different competitions nor spread over several years nor the result of a punishment leading to spectator exclusion. Teams with relatively equal playing strength in the same competition can be compared first with and then without spectators. Certainly, factors that cannot be considered in this paper play a role, too, such as the return of injured key players through the COVID-19 break, while others were suspended after positive virus tests, different incentives at the end of the season by fixed table positions, differences in the game schedule before and after the break as well as different preparations in the lockdown. However, despite these limitations, there has never been such comparability of matches with and without spectators.

Due to the almost identical conditions, we have therefore decided to examine the home bias only in the 2019/20 season for the first German football league and to compare the 83 ghost games with just the 83 (of 223) matches with spectators between the same teams before. In addition to the final results of the games, we collected various variables.

In the following, we discuss the literature relevant to this topic in the next section, form hypotheses based on the literature in the following section, describe the data we have collected, analyse these data, discuss the results and conclude with an outlook.

\section{Literature Review}

Initial research on the home bias is by Schwartz and Barsky (1977), reporting that this bias existed in selected American team sports over long periods of time. Biermann (2011) speaks of an existing home advantage but one that dwindles over time, based on the results of a study by Palacios-Huerta (2004) of English football. Between 1888 and 1915 the home advantage was 56.6\% and between 1983 and 1996 it was only 47.4\% (Palacios-Huerta 2004). Biermann (2011) attributes this to the increasing professionalization of football as well as the differentiable economic possibilities of the clubs and the resulting performance. Specifically for the first German Bundesliga, Strauß and Höfer (2001) determined a distribution of 53.3\% victorious matches of the home team from the 1963/64 to the 1997/98 season compared to $26.0 \%$ draws and $20.7 \%$ away wins.

In the literature several reasons are discussed for the home bias. Schwartz and Barsky (1977) mention the journey of the away team, the familiarity of the environment (see also Loughhead et al. 2003, Moore and Brylinsky 1995) and the spectators. Courneya and Carron (1992) add competition rules to these factors and Wallace et al. (2005) append refereeing behaviour (see also Sutter and Kocher, 2004). The tactical orientation of the teams can play a role, too. There are also differences between countries (Pollard 2006).

The factor of travel in the first investigations seems more questionable now in view of the ever increasing professionalization of the teams and the rising 
convenience of travel. Accordingly, Clarke and Norman (1995) have found already in the 1990s that travel factors no longer played a practical role in determining the home advantage. Competition rules are more likely to be important in other sports, whereas in football they seem to favour the home team only in tournaments such as world championships where the home team usually does not have to expect very tough opponents in its group (Strauß and MacMahon 2019) or is automatically qualified for the group stage. The familiarity of the playing ground should not play a major role in the outcome of the game, too, given that the conditions on the fields and their surroundings, such as the booths and benches are now almost identical for the professional teams.

The influence of the spectators remains as a potentially important factor. The same is true for the refereeing decisions that seem to be more benign when the home team commits fouls compared to away teams (Sapp et al. 2018). Frondel and Schubert (2016) find a correlation between the card spread and a decreasing chance of winning. Moreover, there could be interactions between the audience (including its noise) and the number of fouls as well as the cards and the resulting standard possibilities, e.g., penalties and free kicks (Nevill et al. 2002). Another result could be inhibitions in duels of a player already cautioned (Nevill and Holder 1999). Dohmen (2008) finds that referees tend to give more extra time when the home team only needs one goal to win. If the home team is already ahead, less extra time is given, which could also be influenced by the spectators. Riedl et al. (2015) confirm this and determined a longer extra time of on average 18 seconds. Better referee training over time could be a reason for the declining home advantage over recent years (Nevill et al. 2013). However, it has not been determined as yet whether influencing referees has a causal influence on the home advantage.

Tactical play is also influenced by the location. In home games, players are more effective in offensive actions and less inclined to take defensive actions due to support from the ranks (Schwartz and Barsky 1977) since teams want to win in front of home crowds and offensive play is conducive to the achievement of this goal (Carmichael and Thomas 2005). Furthermore, the audience itself has a direct impact on the players. For example, the volume of the audience is perceived in a negative way to be louder by away teams than by home teams (Barnard et al. 2011). Furthermore, players have higher self-confidence and conviction before home matches and less fear of the game (Bray et al. 2002). This could become a self-fulfilling prophecy. Athletes go into a home or away game with different expectations (Fothergill et al. 2012, Jurkovac 1985). When teams perceive a home advantage or an away disadvantage, their performances may differ even if no (other) advantage or disadvantage exists (Strauß and MacMahon 2019). Home teams have also higher resistance forces, e.g., by measuring the level of testosterone, seeing the away teams as intruders into their territory (Carre et al. 2006).

Reade et al. (2021) analyse 160 European ghost matches and thirty-three thousand matches with spectators in various national and international competitions from the 2002/03 season until April 2020, just before the ghost games analysed by us. They found that $36 \%$ of home matches were won in empty stadiums compared 
to $46 \%$ of home matches in full stadiums. Taking into account the strength of the teams, this difference is not statistically significant. Most of these matches were played as ghost games because misconduct by one of the teams or its fans took place before. Furthermore, they show that differences in refereeing behaviour could be observed. Away teams generally received more yellow cards than home teams but in matches without an audience this difference was significantly lower.

Now there are several studies analysing ghost games because of COVID-19 as we do. Fischer and Haucap (2021) examine the first three leagues in Germany. They find a decline in the home advantage in the first league but no significant change in the second and third league by ghost games. Their main explanation is the reduction in the number of spectators that is higher in the first league. Other relevant factors in their investigation are tracks in the stadium, the travel distance, derbies and matches within the week. McCarrick et al. (2021) examine the change of the home bias in ghost matches in 15 different leagues from the 2019/2020 season and find that referees distribute fewer punitive sanctions against the away team and that the home team's performance decreases.

Bryson et al. (2021) analyse 1,498 ghost games and argue that the absence of a biased home crowd has no effect on the final outcome of these games. However, they find a reduction in yellow cards for away teams compared to home teams by a third. Endrich and Gesche (2020) also find that the disadvantage of away teams regarding yellow cards and given fouls is reduced in games without spectators in the first and second German league. Similarly, Cueva (2020), using data from 41 professional leagues in 30 countries, demonstrates that the disadvantage to away teams in terms of card allocation decreases during the period of spectator exclusion. Sors et al. (2021) show that spectators can influence the referee and consequently the outcome of the game. Scoppa (2021) studies top European leagues and finds a decrease in the home advantage in various performance measures and in decisions on fouls, cards and penalties. Cross and Uhrig (2020) show for the top 4 leagues in Europe (Premier League, Bundesliga, Serie A and La Liga) a disappearance of the home bias using the indicator home goals minus away goals. Correia-Oliveira and Andrade-Souza (2021) also find that there is an effect on the home bias in the 2019/2020 season. Moreover, Hill and Van Yperen (2021) find a significant change in the home bias in Germany. These results are also observed by Tilp and Thaller (2020). However, Wunderlich et al. (2021) do not find a significant decrease in the home bias in their study of professional and amateur matches.

Ferraresi and Gucciardi (2020) choose another perspective and find different changes of the home bias for teams with different performance levels and spectator numbers. In contrast, Sánchez and Lavín (2021) do not find any significant differences in the distribution of wins, draws and losses, with the exception of the German and Spanish top leagues. Nevertheless, statistically insignificant tendencies in this respect are recognisable in other leagues as well. An absence of the spectators can also have major economic or financial consequences, as Drewes et al. (2021) show. Finally, a disappearance of the home bias can also be observed in other sports. Ehrlich and Ghimire (2020) use data from the first American baseball league and observe a disappearance of home bias, too. 


\section{Hypotheses}

On the basis of the literature review and our own considerations, we formulate three hypotheses that can be tested empirically. As shown in the last section, the home advantage can depend on various factors, with spectators usually being the main factor. So our first hypothesis is (in accordance with Reade et al. 2021, and Fischer and Haucap 2021):

\section{1) The home bias disappears in ghost games.}

Further we try to examine the influence of the spectators not only directly on the result but also on parameters influencing this result. As explained in the previous section, the referee plays a role in the outcome of the game by giving yellow and red cards and deciding about extra time. At the same time, the performance of the referee is influenced by the presence of spectators leading to our second hypothesis:

\section{2) The referee's decisions no longer benefit the home team without spectators.}

The teams' performance plays the main role in the outcome, so we survey various performance parameters like distance run in $\mathrm{km}$, passes accuracy, possession, tackles won and shots needed to score a goal to test our third hypothesis:

3) The performance of the home teams becomes weaker without spectators and at the same time that of the away team becomes stronger.

\section{Data}

There were 306 matches in Germany's first football league (of men) in the season 2019/20. The first 223 games were played under normal conditions with spectators. These were mainly the matches of the match days 1 to 25 . Only two matches of these match days took place later without spectators. One was the game between Borussia Mönchengladbach and the FC Köln of the 21st match day, which was played on 11 March 2020 immediately before the break by COVID-19 because it was cancelled on the original date due to a storm warning by the German Weather Service and resulting safety concerns. The other match between Werder Bremen and Eintracht Frankfurt of the 24th match day was initially delayed only shortly due to a tight schedule because of Eintracht Frankfurt's participation in the Europa League, but was postponed longer to 3 June 2020 due to the COVID-19 break. From 16 August 2019 to 8 March 2020 Bundesliga matches were played under regular conditions. The matches continued on 16 May 2020 with the 26th match day. From that date until the 34th match day on 27 June 2020, all matches were played with spectators excluded. Together with the two matches mentioned above, 83 matches were played without spectators. 
Our observation period is therefore exactly one football season. Furthermore, only Bundesliga matches are taken into account and not matches of other competitions like German cup games or the Champions League, as these competitions have their own dynamics and teams from different leagues participate.

We have collected various data for the match days. For the question of the extent of the home bias during the current Bundesliga season, we recorded the final results for goals scored and the distribution of home wins, draws and away wins. Further indicators of the teams' playing style are the number of scored goals, the distance run in kilometres, the passes accuracy, the ball possession, the tackles won and the fouls committed. The fouls committed are just as decisive for the assessment of the referee's behaviour as the cards dealt to each team. We only consider cards for players, not those for officials. Furthermore, we just count the number of cards, not the reasons such as fouls, complaints or taking off the jersey after scoring a goal. The score in the 90th minute and the given extra time also play a decisive role in assessing the behaviour of the referee. For the extra time, the actual extra time and not the displayed extra time was used as these can sometimes vary considerably and the referee can especially influence the former. We have collected all data relevant to our research with one exception from kicker.de, the homepage of the leading football magazine in Germany.

The exception is the data on market values that we have collected at transfermarkt.de for different moments in time. This seems necessary to evaluate whether a possible disappearing home advantage in the ghost games is merely due to a random distribution of the better teams as away teams. Therefore, it makes sense to choose different points in time to collect these data to take into account the changes in the strengths of the teams during the period and possible transfer activities. This appears to be a better indicator than the table position because the results to be investigated are directly fed into the table. Accordingly, we have chosen the value of the teams on transfermarket.de on 15 August 2019 for match days 1 to 7 . From match day 8 to the end of the first half, the 17th match day, we have taken the values on 15 October 2019. The team values on 15 January 2020 are the reference values for match days 18 to 25 , the last match day before the COVID-19 break. Major changes are expected at this value due to the transfer phase in winter. The transfer values from the restart of the league on 16 May 2020 are taken for the match days 26 to 34 . They are lower than before the Corona break due to the changed financial possibilities of the clubs but only the relative values of playing teams are relevant for us.

\section{Empirical Results}

We examine the data of the season 2019/20 regarding differences between matches played under normal conditions and ghost games. First we look at descriptive statistics, then use various statistical test procedures, and finally present results of regression models. 


\section{Descriptive Statistics}

We investigated the entire season as well as only the mirrored games together with the ghost games. The latter reduces the data set of matches under regular conditions (RG) from 223 to 83 but has the advantage that the same teams play against each other and matches between other teams are not considered. Accordingly, the results are somewhat stronger (but similar to those with all games of the season, which are available upon request). Table 1 shows a comparison of the descriptive statistics of the 83 games under regular conditions and the 83 ghost games (GG) without spectators.

Looking at Table 1, a decline in home wins from $48.2 \%$ before the COVID19 break to $32.5 \%$ home wins after the break can be observed. (This is similar to the $45.3 \%$ of home wins on average in the ten seasons before, from 2009/10 to $2018 / 19$. In these ten seasons, away wins occurred in $30.1 \%$ of matches on average and draws accounted for the remaining $24.6 \%$.) In combination with the draws, which increased from $19.3 \%$ to $22.9 \%$, this results in on average 0.44 points less at home. The away wins increased from $32.5 \%$ to $44.6 \%$. In addition, the difference in goals from the home team's point of view is reversed from a positive value of 0.433 to a negative value of -0.228 . On a purely descriptive level, our first hypothesis could be confirmed but other tests are needed to establish this.

For the descriptive assessment of our second hypothesis that refereeing behaviour is less favourable to the home team in ghost games, we look at the overtime at the end of the game and the cards given to the teams. The extra time at the end of the game decreases from 3.734 to 3.228 minutes, which supports our hypothesis. The number of cards for the home team increases for ghost games and decreases for away teams. The variable "Cards difference (H-A)" shows this clearly by its negative value of -0.614 for regular games and its positive value of 0.144 for ghost games. This tendency is also visible when yellow and red cards are differentiated. For the home team, only the number of red cards is decreasing but the red cards for the away teams are decreasing more. All of this is in accordance with our second hypothesis. 
Table 1. Descriptive Statistics of the Season 2019/20

\begin{tabular}{|c|c|c|c|c|c|c|c|c|c|c|}
\hline \multirow[b]{2}{*}{ Variables } & \multicolumn{2}{|c|}{$\mathbf{N}$} & \multicolumn{2}{|c|}{ Minimum } & \multicolumn{2}{|c|}{ Maximum } & \multicolumn{2}{|c|}{$\mathbf{M}$} & \multicolumn{2}{|c|}{ SD } \\
\hline & RG & GG & RG & GG & RG & GG & RG & GG & RG & GG \\
\hline Home win & 83 & 83 & 0 & 0 & 1 & 1 & 0.482 & 0.325 & 0.503 & 0.471 \\
\hline Draw & 83 & 83 & 0 & 0 & 1 & 1 & 0.193 & 0.229 & 0.397 & 0.423 \\
\hline Away win & 83 & 83 & 0 & 0 & 1 & 1 & 0.325 & 0.446 & 0.471 & 0.500 \\
\hline Home points & 83 & 83 & 0 & 0 & 3 & 3 & 1.638 & 1.204 & 1.366 & 1.314 \\
\hline Away points & 83 & 83 & 0 & 0 & 3 & 3 & 1.168 & 1.566 & 1.333 & 1.345 \\
\hline Diffpoints & 83 & 83 & -3 & -3 & 3 & 3 & 0.469 & -0.361 & 2.670 & 2.625 \\
\hline Market value in Mio. $€(\mathrm{H})$ & 83 & 83 & 27.600 & 26.530 & 882.650 & 756.580 & 262.570 & 228.199 & 219.123 & 195.097 \\
\hline Market value in Mio. $€(A)$ & 83 & 83 & 27.600 & 26.530 & 882.650 & 756.580 & 257.579 & 231.754 & 215.261 & 196.101 \\
\hline Market value difference (H-A) & 83 & 83 & -798.000 & -716.130 & 846.650 & 687.800 & 4.991 & -3.555 & 311.049 & 282.023 \\
\hline Goals $(\mathrm{H})$ & 83 & 83 & 0 & 0 & 8 & 6 & 1.855 & 1.433 & 1.466 & 1.390 \\
\hline Goals (A) & 83 & \begin{tabular}{|c|}
83 \\
\end{tabular} & 0 & 0 & 5 & 6 & 1.421 & 1.662 & 1.308 & 1.391 \\
\hline Goals difference (H-A) & 83 & 83 & -5 & -5 & 8 & 5 & 0.433 & -0.228 & 2.142 & 2.216 \\
\hline Extra time 2 nd half (min) & 83 & 83 & 0 & 0 & 10 & 7 & 3.734 & 3.228 & 1.994 & 1.727 \\
\hline Shots on target $(\mathrm{H})$ & 83 & \begin{tabular}{|c|}
83 \\
\end{tabular} & 4 & 4 & 29 & 34 & 15.975 & 13.325 & 5.280 & 5.310 \\
\hline Shots on target (A) & 83 & 83 & 2 & 4 & 24 & 26 & 11.879 & 11.831 & 4.715 & 4.520 \\
\hline Shots/goals $(\mathrm{H})$ & 83 & 83 & 0 & 0 & 29 & 22 & 7.644 & 6.081 & 6.259 & 5.455 \\
\hline Shots/goals (A) & 83 & \begin{tabular}{|c|}
83 \\
\end{tabular} & 0 & 0 & 24 & 18 & 6.035 & 5.946 & 5.737 & 4.670 \\
\hline Distance run in $\mathrm{km}(\mathrm{H})$ & 83 & 83 & 104.100 & 105.380 & 127.950 & 126.390 & 116.579 & 115.198 & 4.368 & 4.691 \\
\hline Distance run in $\mathrm{km}(\mathrm{A})$ & 83 & 83 & 103.640 & 105.740 & 129.350 & 124.210 & 116.108 & 115.185 & 5.061 & 4.411 \\
\hline Passes accuracy \% (H) & 83 & 83 & 64 & 65 & 94 & 89 & \begin{tabular}{|l|}
78.554 \\
\end{tabular} & 79.674 & 6.453 & 6.165 \\
\hline Passes accuracy \% (A) & 83 & \begin{tabular}{|c|}
83 \\
\end{tabular} & 60 & 57 & 92 & 90 & 75.855 & 78.337 & 7.148 & 7.307 \\
\hline Possession \% (H) & 83 & 83 & 29 & 27 & 76 & 72 & 53.048 & 51.253 & 11.244 & 11.261 \\
\hline Possession \% (A) & 83 & 83 & 24 & 28 & 71 & 73 & 46.951 & 48.746 & 11.244 & 11.261 \\
\hline Tackles won \% (H) & 83 & \begin{tabular}{|c|}
83 \\
\end{tabular} & 39 & 37 & 63 & 60 & 50.674 & 50.650 & 4.859 & 4.723 \\
\hline Tackles won \% (A) & 83 & 83 & 37 & 40 & 61 & 63 & \begin{tabular}{|l|}
49.325 \\
\end{tabular} & 49.349 & 4.859 & 4.723 \\
\hline Fouls committed $(\mathrm{H})$ & 83 & 83 & 6 & 4 & 23 & 22 & 11.819 & 12.144 & 3.700 & 3.693 \\
\hline Fouls committed (A) & 83 & 83 & 5 & 3 & 22 & 20 & 12.072 & 11.891 & 3.780 & 4.150 \\
\hline Yellow cards $(\mathrm{H})$ & 83 & \begin{tabular}{|c|}
83 \\
\end{tabular} & 0 & 0 & 6 & 6 & 1.722 & 2.000 & 1.193 & 1.538 \\
\hline Yellow cards (A) & 83 & 83 & 0 & 0 & 6 & 4 & 2.228 & 1.867 & 1.364 & 1.102 \\
\hline Red cards $(\mathrm{H})$ & 83 & \begin{tabular}{|l|}
83 \\
\end{tabular} & 0 & 0 & 1 & 1 & 0.036 & 0.024 & 0.188 & 0.154 \\
\hline Red cards (A) & 83 & \begin{tabular}{|c|}
83 \\
\end{tabular} & 0 & 0 & 1 & 1 & 0.084 & 0.024 & 0.280 & 0.154 \\
\hline Cards $(\mathrm{H})$ & 83 & \begin{tabular}{|l|}
83 \\
\end{tabular} & 0 & 0 & 7 & 6 & 1.795 & 2.096 & 1.266 & 1.551 \\
\hline Cards (A) & 83 & 83 & 0 & 0 & 6 & 5 & 2.409 & 1.951 & 1.344 & 1.168 \\
\hline Cards difference $(\mathrm{H}-\mathrm{A})$ & 83 & \begin{tabular}{|l|}
83 \\
\end{tabular} & -4 & -3 & 5 & 4 & $-0,614$ & 0.144 & 1.681 & 1.639 \\
\hline
\end{tabular}

$\mathrm{N}=$ Sample Size. $\mathrm{M}=$ Mean. $\mathrm{SD}=$ Standard Deviation. $\mathrm{RG}=$ Regular Games. $\mathrm{GG}=$ Ghost Games. $\mathrm{H}=\mathrm{Home}$ Team. $\mathrm{A}=$ Away Team.

For our third hypothesis of less pronounced performance indicators for the home team and simultaneously a stronger away team in ghost games, it can be stated that fewer shots are fired by the home team. However, the home team needs 1.563 fewer shots to score a goal in ghost games than before. For the away team both values are almost unchanged. Likewise, no large differences can be found in the duels won. For both teams, the mileage decreases slightly during the game but it decreases more for the home team than for the away team. In any case, the accuracy of passes and the distribution of ball possession have developed in the direction of our hypothesis, since the first one increases more for the away time while the second one decreases for the home team and increases for the away team. All in all, our third hypothesis can be partially confirmed just looking at the descriptive statistics. More meaningful statistic tests are presented in the next subsection.

\section{Tests of Significance}

To examine our hypotheses further, we use tests of statistical significance. First, Chi-square tests are performed for the distribution of home wins, draws and 
away wins. There are significantly (at the 5\% level with an error probability of 4.0\%) less home wins while the increases in draws and away wins are not statistically significant. For the other variables, depending on their distributions, different kinds of tests are used as shown in Table 2 . All variables were tested, but apart from draw and away win only those are listed in Table 2 that are statistically significant at least weakly with a level of error probability of less than $10 \%$.

Table 2. Different Statistical Tests (Grouped by Type of Game)

\begin{tabular}{|c|c|c|c|c|c|c|c|c|c|c|}
\hline \multirow[t]{2}{*}{ Variables } & \multicolumn{3}{|c|}{ RG } & \multicolumn{3}{|c|}{ GG } & \multirow[b]{2}{*}{ Test } & \multirow[b]{2}{*}{$\begin{array}{l}\text { Sig. (2- } \\
\text { tailed) }\end{array}$} & \multicolumn{2}{|c|}{$95 \%$ CI } \\
\hline & $\mathbf{M}$ & SD & $\mathbf{N}$ & $\mathbf{M}$ & SD & $\mathbf{N}$ & & & LV & UV \\
\hline Home win & 0.482 & 0.503 & 83 & 0.325 & 0.471 & 83 & $\mathrm{P} \chi^{2}$ & $0.040^{* * *}$ & & \\
\hline Draw & 0.193 & 0.397 & 83 & 0.229 & 0.423 & 83 & $\mathrm{P} \chi^{2}$ & 0.568 & & \\
\hline Away win & 0.325 & 0.471 & 83 & 0.446 & 0.500 & 83 & $\mathrm{P} \chi^{2}$ & 0.111 & & \\
\hline Home points & 1.639 & 1.367 & 83 & 1.205 & 1.314 & 83 & MWU & $0.045^{* *}$ & & \\
\hline Away points & 1.169 & 1.333 & 83 & 1.566 & 1.345 & 83 & MWU & $0.045^{\text {*** }}$ & & \\
\hline Diffpoints & 0.470 & 2.670 & 83 & -0.361 & 2.625 & 83 & MWU & $0.045^{\text {*** }}$ & & \\
\hline Goals $(\mathrm{H})$ & 1.855 & 1.466 & 83 & 1.434 & 1.390 & 83 & KS & $0.040^{* *}$ & & \\
\hline Goals difference (H-A) & 0.434 & 2.142 & 83 & -0.229 & 2.216 & 83 & t-Test & $0.052 *$ & -0.005 & 1.331 \\
\hline Extra time 2nd half (min) & 3.735 & 1.994 & 83 & 3.229 & 1.727 & 83 & $\mathrm{t}$-Test & $0.082 *$ & -0.066 & 1.078 \\
\hline Shots on target $(\mathrm{H})$ & 15.976 & 5.280 & 83 & 13.325 & 5.310 & 83 & $\mathrm{t}$-Test & $0.002 * * *$ & 1.028 & 4.274 \\
\hline Distance run in $\mathrm{km}(\mathrm{H})$ & 116.580 & 4.368 & 83 & 115.198 & 4.692 & 83 & $\mathrm{t}$-Test & $0.051^{*}$ & -0.007 & 2.770 \\
\hline Passes accuracy (A) & 75.855 & 7.149 & 83 & 78.337 & 7.307 & 83 & $\mathrm{t}$-Test & $0.028^{* * *}$ & -4.697 & -0.266 \\
\hline Yellow cards (A) & 2.229 & 1.364 & 83 & 1.868 & 1.102 & 83 & $\mathrm{t}$-Test & $0.062 *$ & -0.019 & 0.742 \\
\hline Red cards (A) & 0.084 & 0.280 & 83 & 0.024 & 0.154 & 83 & $\mathrm{P} \chi^{2}$ & $0.087^{*}$ & -0.009 & 0.129 \\
\hline Cards (A) & 2.410 & 1.344 & 83 & 4.050 & 2.203 & 83 & t-Test & $0.020^{\text {*** }}$ & 0.072 & 0.844 \\
\hline Cards differnce (H-A) & -0.614 & 1.681 & 83 & 0.145 & 1.639 & 83 & $\mathrm{t}$-Test & $0.004^{* * *}$ & -1.268 & -0.250 \\
\hline
\end{tabular}

The significant decrease in home wins as well as the significant decreases in home goals and the goal difference from the home team's point of view support our hypothesis 1 . Also the significant decrease in home points and significant increase in away points show that the home advantage disappears without spectators. Moreover, the variable "Diffpoints", which shows the difference of the scored points from the point of view of the home team, is significantly reduced in favour of our hypothesis.

Regarding hypothesis 2 on the change in referee behaviour, the variable "Extra time 2nd half ( $\mathrm{min}$ )" is significant (weakly on the $10 \%$ level). The difference between the cards of the home and away teams is even more significant (on the $1 \%$ level). Moreover, the change in the number of cards for away teams is statistically significant (on the 5\% level), while it is weakly so (on the $10 \%$ level) for their yellow and red cards.

For hypothesis 3 , there are significantly (on the $1 \%$ level) less shots fired on target by the home team, while there is a significantly higher pass accuracy of the away team. Furthermore, the home team runs significantly (weakly on the $10 \%$ level) less during the ghost games. However, as mentioned above, all other variables listed in Table 1 but not in Table 2 have no significant difference between regular games and ghost games. 
For the differences in goals, cards and market values between home and away teams, additional t-tests are carried out to check whether these differences are significantly different from 0 . The home advantage of goals scored is statistically significant (but only weakly at the 10\% level) before the COVID-19 break but not after the break. Likewise, the home advantage regarding the distribution of cards is significant (at the 1\% level) before but not after the break. The difference in the market values of the two teams is not significant in either case.

\section{Regression Results}

To test our hypotheses further, we use regressions that control the influence of several variables at the same time. We regress home wins, the difference in cards and the length of extra time. Concerning hypothesis 3 , the performance variables have not provided significant regression results such that they are not discussed further in this section.

For home wins as the dependent variable, a binary logistic regression is suitable. First, we have included all variables listed in Table 1 that are not interdependent. Then we removed all insignificant variables, like the performance variables, and ran a new regression.

Table 3 shows the results with the statistically significant variables. Ghost games are significantly negative for home wins, confirming our hypothesis 1 . The variable "Market value difference $(\mathrm{H}-\mathrm{A})$ " has a significantly positive influence on home wins (on the $1 \%$ level). Furthermore, the length of extra time has a significantly negative influence on home wins. However, this could be a case of reverse causality if the referee gives more overtime in case the home teams is one goal behind or has the chance to win a tied game.

Table 3. Binary Logistic Regression for Home Wins ${ }^{1}$

\begin{tabular}{|l|c|c|c|c|c|}
\hline \multirow{2}{*}{ Independent variables } & \multirow{2}{*}{$\mathbf{B}$} & \multirow{2}{*}{$\operatorname{Exp}(\mathbf{B})$} & \multirow{2}{*}{ Sig. } & \multicolumn{2}{|c|}{ 95 \% CI } \\
\cline { 5 - 6 } & & & & $\mathbf{L V}$ & $\mathbf{U V}$ \\
\hline Type of game & -0.828 & 0.437 & $0.018^{* *}$ & 0.220 & 0.866 \\
\hline Market value difference (H-A) & 0.002 & 1.002 & $0.001 * * *$ & 1.001 & 1.003 \\
\hline Extra time 2nd half (min) & -0.210 & 0.810 & $0.027 * *$ & 0.672 & 0.977 \\
\hline
\end{tabular}

$\mathrm{B}=$ Regression Coefficient. $\operatorname{Exp}(\mathrm{B})=$ Exponentiation of B, Odds Ratio. Sig. $=$ Significance. $\mathrm{CI}=$ Confidence Interval for $\operatorname{Exp}(\mathrm{B}) . \mathrm{LV}=$ Lower Value. UV $=$ Upper Value. ${ }^{*} \mathrm{p}<0.10 .{ }^{*} \mathrm{p}<0.05$. $* * * \mathrm{p}<0.01$.

There are different regression models that could be used for "Cards difference (H-A)" as independent variable. The variable is sufficiently normally distributed such that a multiple linear regression is possible. To include independent variables in the model, we proceeded as before, starting with all of them without interdependencies and then repeating the regression with the significant ones only. Four of them remain in the model as shown in Table 4. The adjusted $R^{2}$ is 0.199 . That means $19.9 \%$ of the variance is explained by this model.

\footnotetext{
${ }^{1}-2$ Log likelihood $=199.946$, Cox \& Snell $R^{2}=0.134$, Nagelkerke $R^{2}=0.182$
} 
Table 4. Multiple Linear Regression for Cards Difference

\begin{tabular}{|l|c|c|c|c|c|c|}
\hline $\begin{array}{l}\text { Independent } \\
\text { variables }\end{array}$ & \multirow{2}{*}{$\begin{array}{c}\text { Std. } \\
\text { Error }\end{array}$} & \multirow{2}{*}{ T } & \multirow{2}{*}{ Sig. } & \multicolumn{2}{|c|}{ 95 \% CI } \\
\hline Type of game & 0.603 & 0.239 & 2.526 & $0.013^{* *}$ & 0.132 & 1.075 \\
\hline Goal difference (H-A) & -0.136 & 0.054 & -2.490 & $0.014^{* *}$ & -0.243 & -0.028 \\
\hline Fouls committed (H) & 0.126 & 0.033 & 3.868 & $<0.001^{* * *}$ & 0.062 & 0.191 \\
\hline Fouls committed (A) & -0.136 & 0.030 & -4.473 & $<0.001^{* * *}$ & -0.196 & -0.076 \\
\hline Constant & -0.406 & 0.509 & -0.797 & 0.427 & -1.412 & 0.600 \\
\hline
\end{tabular}

$\mathrm{B}=$ Regression Coefficient. Std. Error $=$ Standard Error. Sig. = Significance. $\mathrm{CI}=$ Confidence Interval for $\operatorname{Exp}(B) . L V=$ Lower Value. UV $=$ Upper Value. $* * p<0.05 . * * * p<0.01$.

The most important result is that the type of game has a significantly positive influence on the difference of cards between home and away teams. Given the fact that home teams get less cards in regular games, this confirms our hypothesis 2 that the home bias in the distribution of cards disappears in ghost games. The difference in goals reduces the difference in cards, meaning that the leading team gets fewer cards. It is not surprising that fouls by the home team have a significantly positive effect on the difference of cards for the home and away team while the fouls of the away team have conversely a significantly negative effect (both on the $1 \%$ and even $1 \%$ level).

For the analysis of "Extra time 2nd half (min)" as dependent variable, the appropriate regression has to be considered again. The deviations from the normal distribution are larger than those for the cards difference but not too large such that a multiple linear regression model can be used again. The variables are chosen as before such that only two independent ones remain in the final regression. The results are shown in Table 5. The adjusted $R^{2}$ of this regression is 0.056 .

Table 5. Multiple Linear Regression for Extra Time

\begin{tabular}{|c|c|c|c|c|c|c|}
\hline \multirow{2}{*}{ Independent variables } & \multirow{2}{*}{ B } & \multirow{2}{*}{$\begin{array}{c}\text { Std. } \\
\text { Error }\end{array}$} & \multirow{2}{*}{$\mathbf{T}$} & \multirow{2}{*}{ Sig. } & \multicolumn{2}{|c|}{$95 \% \mathrm{CI}$} \\
\hline & & & & & $\mathbf{L V}$ & UV \\
\hline Type of game & -0.633 & 0.286 & -2.209 & $0.029 * *$ & -1.198 & -0.067 \\
\hline Goal difference $(\mathrm{H}-\mathrm{A})$ & -0.191 & 0.065 & -2.929 & $0.004 * * *$ & -0.320 & -0.062 \\
\hline Constant & 3.818 & 0.202 & 18.882 & $<0.001 * * *$ & 3.419 & 4.217 \\
\hline
\end{tabular}

$\mathrm{B}=$ Regression Coefficient. Std. Error $=$ Standard Error. Sig. $=$ Significance. $\mathrm{CI}=$ Confidence Interval for $\operatorname{Exp}(B) . \mathrm{LV}=$ Lower Value. UV $=$ Upper Value. ${ }^{* *} \mathrm{p}<0.05 .{ }^{* * *} \mathrm{p}<0.01$.

Ghost games significantly reduce the overtime given by the referee. Also statistically significant is the goal difference (on the $1 \%$ level). More goals by the home team decrease the overtime. This could be due to a home bias by the referee who gives (only) the home team more time if it needs this time to win or not to lose.

\section{Discussion}

We can confirm our first hypothesis that the home bias disappears in ghost games. A purely descriptive examination of the results shows a decline in home wins, home points scored and goals scored by home teams. In statistical tests the decreases of these variables are significant and also in the tests of the individual 
samples the goals differences in favour of the home team is significantly positive only before the COVID-19 break (and only weakly on the 10\% level). Nevertheless, the disappearance of the home bias does not turn into a significant advantage for the away team or a home disadvantage. Even the increases of away wins and draws are not statistically significant. The binary logistic regression confirms the disappearance of the home advantage even controlling for other variables like differences in team values that are very important by themselves. This confirmation of our first hypothesis follows the results of Reade et al. (2021) as well as Fischer and Haucap (2021), despite some differences in the examination of the home bias.

Regarding our second hypothesis that referees' decisions no longer benefit the home team without spectators, we find significant decreases in the yellow, red and total number of cards for away teams (for the yellow and red ones only weakly on the $10 \%$ level). The away teams committed fewer fouls in the ghost games, too, but this difference is not significant. The difference in cards the home and away team got is significantly changed (on the $1 \%$ level). In regular games the home teams got significantly (at the 1\% level) less cards and in the ghost games they got insignificantly more. This is also confirmed by the linear regression model, in which the ghost games have a significant effect that evaporates any home bias in this regard.

As a further indicator of the change in refereeing behaviour, we use the length of extra time at the end of the game. The linear regression shows a significant influence of the type of match day on the length of extra time but no significant influence of fouls that could cause delays. However, the goal difference from the point of view of the home team has a significantly (on the $1 \%$ level) negative influence on the extra time. This is an indicator of a home bias because games are finished sooner when the home team is leading whereas they go on longer if the home team needs one more goal to win or reach a draw. This can explain why there is a significantly negative sign of the length of extra time in the regression model of the home win. In sum, there is strong evidence for a home bias in the refereeing behaviour in regular matches that is at least reduced if not eliminated in ghost games in accordance with our hypothesis.

Our third hypothesis that the performance of the home teams becomes weaker and of the away team becomes stronger without spectators cannot be confirmed. There are only significant differences in the performance characteristics distance run by the home team (weakly on the $10 \%$ level), passes accuracy of the away team (on the normal 5\% level) and shots on target by the home teams (on the $1 \%$ level). Although these differences fit into the direction of the hypothesis as the home teams becomes weaker and the away team stronger, it should be noted that the mileage of away teams also decreases, although insignificantly, while the passes accuracy also increases insignificantly for the home team. The number of shots on target by the home team decreases significantly but the number of shots required per goal decreases insignificantly such that these variables could cancel each other out. It should also be noted that none of the performance variables is significant in the binary logistic regression for the home bias, and therefore the performance characteristics recorded here do not appear to have any relevant 
influence on the achievement of a home win.

\section{Conclusions and Outlook}

In summary, the disappearance of the home advantage in ghost games can be seen from the pure results as in previous investigations without the emergence of an away advantage. While the performance measures of the teams surveyed here have no relevant influence on this, which is an interesting result in itself, the referees' behaviour changes significantly and contributes to the disappearance of the home bias.

This has some implications for teams and their trainers as well as leagues and their organisers. Teams have to be aware that the situation in ghost games is different. The home bias cannot be taken for granted and the strategies should be adjusted accordingly. However, the normal team performance like running and passing does not seem to make the crucial difference. The influence on the referees is more important, at least according to the results of our study. Perhaps the referees should be more shielded from the spectators in the future when the stadiums will be full again. The greater influence of video referees is going in that direction. The referees on the ground should be made aware of the home bias and their role in it such that they can try to counteract it consciously. In a way, the home bias is unfair, but taking it away within a season is unfair, too, because it is not equalised by an equivalent advantage for the other team in the second part of the season. The same is true when the ghost games will end someday within a season. Letting in only spectators of the home team, as has been discussed by some politicians, would be even worse.

As already mentioned in the introduction, there were external conditions besides the (missing) spectators that influenced the results and are not included in our evaluation, such as the return of key players, different incentives at the end of the season by the table positions, differences in the game schedule before and after the break, different training conditions and preparations of the teams, activities on the transfer market in winter and some rule changes as the possibility to change five players instead of only three during a ghost game. In a perfect experiment, these effects would all be non-existent and games would take place under exactly the same conditions with and without spectators. However, this is not feasible and there has never been such comparability of games with and without spectators as in the season 2019/20.

Just as the German Bundesliga has made a kick-off for football, research on this can be the prelude to a wide range of different research in the sports field on the effects of the COVID-19 pandemic. Further first leagues in Europe should be analysed and also lower leagues could be included, as Fischer and Haucap (2021) have already done for the second and third leagues in Germany. The Economist (2020) also looked at several leagues in Europe and descriptively found a decline but no disappearance of the home advantage while the home bias of referees vanished completely. In addition, possible differences and similarities between men's and women's football could be surveyed. Other variables, other competitions 
besides league games as well as other sports could also be analysed.

\section{References}

Barnard A, Porter S, Bostron J, Termeulen R, Hambric S (2011) Evaluation of crowd noise levels during college football games. Noise Control Engineering Journal 59(6): 667680.

Biermann C (2011) Die Fußball-Matrix: Auf der Suche nach dem perfekten Spiel. (The soccer matrix: in search of the perfect game). Cologne: Kiepenheuer \& Witsch.

Bray SR, Jones MV, Owen S (2002) The influence of competition location on athletes' psychological states. Journal of Sports Behavior 25(3): 231-242.

Bryson A, Dolton P, Reade JJ, Schreyer D, Singleton C (2021) Causal effects of an absent crowd on performances and refereeing decisions during COVID-19. Economic Letters 198(Jan): 109664.

Carmichael F, Thomas D (2005) Home-field effect and team performance: evidence from English premiership football. Journal of Sports Economics 6(3): 264-281.

Carre J, Muir C, Belanger J, Putnam S (2006) Pre-competition hormonal and psychological levels of elite hockey players: Relationship to the home advantage. Psychology and Behavior 89(3): 392-398.

Clarke SR, Norman JM (1995) Home advantage of individual clubs in English soccer. The Statistician 44(4): 509-521.

Correia-Oliveira CR, Andrade-Souza VA (2021) Home advantage in soccer after the break due to COVID-19 pandemic: does crowd support matter? International Journal of Sport and Exercise Psychology (forthcoming).

Courneya KS, Carron A V (1992) The home advantage in sport competitions: a literature review. Journal of Sport and Exercise Psychology 14(4): 13-27.

Cross J, Uhrig R (2020) Do fans impact sports outcomes? A COVID-19 natural experiment. Retrieved from: https://dx.doi.org/10.2139/ssrn.3705085. [Accessed 11 October 2021]

Cueva C (2020) Animal spirits in a beautiful game: testing social pressure in professional football during the COVID-19 lockdown. Retrieved from: https://osf.io/download/5f 5b5a452c735500aeea1e5f/. [Accessed 11 October 2021]

Deutscher Fußball-Bund (1999) 100 Jahre DFB: Die Geschichte des deutschen FußballBundes. (100 years DFB: the history of the German Football Association). Berlin: Sportverlag.

Deutscher Fußball-Bund (2020) Task Force Sportmedizin/Sonderspielbetrieb im Profifußball, Version 2.1: Stadien, Trainingsstätten, Hotels, Häusliche Hygiene. (Task force sports medicine/special game operation in professional football, version 2.1: stadiums, training centers, hotels, domestic hygiene). Retrieved from: https://media.dfl.de/sites/ 2/2020/05/2020-05-12-Task-Force-Sportmedizin_Sonderspielbetrieb_Version-2.1. pdf. [Accessed 11 October 2021]

Dohmen TJ (2008) The influence of social forces: evidence from the behavior of football referees. Economic Inquiry 46(3): 411-424.

Drewes M, Daumann F, Follert F (2021) Exploring the sports economic impact of COVID-19 on professional soccer. Soccer \& Society 22(1-2): 125-137.

Ehrlich J, Ghimire S (2020) COVID-19 countermeasures, Major League Baseball, and the home field advantage: simulating the 2020 season using logit regression and a neural network. F1000Research. Retrieved from: https://f1000research.com/articles/9-414. [Accessed 12 October 2021]. 
Endrich M, Gesche T (2020) Home-bias in referee decisions: evidence from 'ghost matches' during the COVID19-Pandemic. Economics Letters 197(Dec): 109621.

Ferraresi M, Gucciardi G (2020) Team performance and audience: experimental evidence from the football sector. Working Paper 94. Pavia: Società Italiana di Economia Pubblica.

Fischer K, Haucap J (2021) Does crowd support drive the home advantage in professional football? Evidence from German ghost games during the COVID-19 pandemic. Journal of Sports Economics 22(8): 871-892.

Fothergill M, Wolfson S, Neave N, Moss M (2012) Perspectives on the home advantage: a comparison of football players, fans and referees. Psychology of Sport and Exercise 13(3): 311-316.

Frondel M, Schubert S (2016) Sieg der Defensive? Evidenz für die 1. Deutsche FußballLiga. (Victory of the defensive? Evidence for the 1st German football league). AStA Wirtschafts- \& Sozialstatistisches Archiv 10(4): 225-246.

Hill Y, Van Yperen N W (2021) Losing the home field advantage when playing behind closed doors during COVID-19: Change or chance? Frontiers in Psychology 12(Apr): 658452.

Jurkovac T (1985) Collegiate basketball players' perceptions of the home advantage. Master Thesis. Bowling Green, Ohio: Bowling Green State University.

Loughhead T, Carron AV, Bray SR, Kim AJ (2003) Facility familiarity and the home advantage in professional sports. International Journal of Sports and Exercise Psychology 1(3): 264-274.

McCarrick D, Bilalic M, Neave N, Wolfson S (2021) Home advantage during the COVID19 pandemic: analyses of European football leagues. Psychology of Sport and Exercise 56(Sep): 102013.

Moore J, Brylinsky J (1995) Facility familiarity and the home advantage. Journal of Sport Behavior 18(4): 302-311.

Nevill AM, Holder RL (1999) Home advantage in sport: an overview of studies on the advantage of playing at home. Sports Medicine 28(4): 221-236.

Nevill AM, Balmer NJ, Williams AM (2002) The influence of crowd noise and experience upon refereeing decisions in football. Psychology of Sport and Exercise 3(4): 261-272.

Nevill AM, Webb T, Watts A (2013) Improved training of football referees and the decline in home advantage post-WW2. Psychology of Sport and Exercise 14(2): 220-227.

Palacios-Huerta I (2004) Structural changes during a century of the world's most popular sport. Statistical Methods and Applications 13(2): 241-258.

Pollard R (2006) Worldwide regional variations in home advantage in association football. Journal of Sports Sciences 24(3): 231-240.

Pollard R (2008) Home advantage in football: a current review of an unsolved puzzle. Open Sports Sciences Journal 1(1): 12-14.

Pollard R, Gómez MA (2014) Components of home advantage in 157 national soccer leagues worldwide. International Journal of Sport and Exercise Psychology 12(3): 218-233.

Pollard R, Pollard G (2005) Long-term trends in home advantage in professional team sports in North America and England (1876-2003). Journal of Sports Sciences 23(4): 337-350.

Reade JJ, Schreyer D, Singleton C (2021) Eliminating supportive crowds reduces referee bias. Economic Inquiry (forthcoming). 
Riedl D, Strauß B, Heuer A, Rubner O (2015) Finale furioso: referee-biased injury times and their effects on home advantage in football. Journal of Sports Sciences 33(4): 327-336.

Sánchez AJ, Lavín JM (2021) Home advantage in European soccer without crowd. Soccer \& Society 22(1+2): 152-165.

Sapp RM, Spangenburg EE, Hagberg, JM (2018) Trends in aggressive play and refereeing among the top five European soccer leagues. Journal of Sports Sciences 36(12): $1346-1354$.

Schwartz B, Barsky SF (1977) The home advantage. Social Forces 55(3): 641-661.

Scoppa V (2021) Social pressure in the stadiums: do agents change behavior without crowd support? Journal of Economic Psychology 82(Jan): 102344.

Sors F, Grassi M, Agostini T, Murgia M (2021) The sound of silence in association football: home advantage and referee bias decrease in matches played without spectators. European Journal of Sport Science 21(12): 1597-1605.

Strauß B, Höfer E (2001) The home advantage in team sports. In A Papaioammou, M Goudas, Y Theodorakis (eds.), Proceedings of the 10th World Congress of Sport Psychology, volume 4, 210-212. Thessaloniki: Christodoulidi Publications.

Strauß B, MacMahon C (2019) Heimvorteil. (Home advantage). In A Güllich, M Krüger (eds.), Sport in Kultur und Gesellschaft, 1-14. Berlin, Heidelberg: Springer.

Sutter M, Kocher M (2004) Favoritism of agents: the case of referees' home bias. Journal of Economic Psychology 25(4): 461-469.

The Economist (2020, July 25) Empty stadiums have shrunk football teams' home advantage. Available at: https://www.economist.com/graphic-detail/2020/07/25/emp ty-stadiums-have-shrunk-football-teams-home-advantage.

Tilp M, Thaller S (2020) COVID-19 has turned home-advantage into home-disadvantage in the German soccer Bundesliga. Frontiers in Sports and Active Living 2(Nov): 593499.

Wallace HM, Baumeister R, Vohs K (2005) Audience support and choking under pressure: a home disadvantage. Journal of Sports Sciences 23(4): 429-438.

Wunderlich F, Weigelt M, Rein R, Memmert D (2021) How does spectator presence affect football? Home advantage remains in European top-class football matches played without spectators during the COVID-19 pandemic. PloS One 16(3): e0248590. 